\title{
Green University and Academic Performance: An Empirical Study on UI GreenMetric and World University Rankings
}

\author{
Kazim Baris Atici (Corresponding Author) \\ Department of Business Administration, Hacettepe University, Ankara, Turkey \\ kba@hacettepe.edu.tr \\ Gokhan Yasayacak \\ Department of Business Administration, Hacettepe University, Ankara, Turkey \\ gkhnyasayacak@gmail.com \\ Yilmaz Yildiz \\ Huddersfield Business School, University of Huddersfield, Huddersfield, UK \\ Y.Yildiz@hud.ac.uk \\ Aydin Ulucan \\ Department of Business Administration, Hacettepe University, Ankara, Turkey \\ aulucan@hacettepe.edu.tr
}




\title{
Green University and Academic Performance: An Empirical Study on UI GreenMetric and World University Rankings
}

\begin{abstract}
The role of higher education institutions in promoting environmental sustainability is not limited to research activities but also covers improving their campus infrastructure into a more environmentfriendly setting as well as updating their curricula to include courses on environment and sustainability. The contemporary concept of 'green university' has been embraced by an increasing number of universities and attracted attention from scholars all over the world. The current study aims to contribute to the recent research stream on green universities by disclosing the relationship between academic performances of the universities and 'being green'. For this purpose, the current research tests (i) whether sustainability relates to the academic performances of universities, (ii) whether the relationship (if it exists) is valid when the academic scores are aggregated to a composite score, (iii) whether the relationship (if it exists) is contingent upon the scores of environmental performance at the country level and (iv) whether the relationship (if it exists) holds for out-of-sample estimations. Utilizing the sustainability scores of the universities published by UI GreenMetric and four major academic ranking systems, the findings of the current research support the earlier discussions on the importance of the environmental sustainability policies implemented by university managements. The results reveal that being green has a reflection on the university rankings, and the environmental sustainability can serve as a competitive advantage for the world universities.
\end{abstract}

Keywords: Environmental Sustainability; Green University; Higher Education; World University Ranking; UI GreenMetric 


\section{Introduction}

The term 'Green' has been introduced to different areas including but not limited to agriculture, energy, production, technology, even used within a broader context as 'green economy'. Its diffusion to higher education at institutional level dates back to the early 90 s with the introduction of the concept, 'greening of the universities'. Starting from the 2000s, particularly after 2010, the term has evolved to more specified concepts as 'green university', 'green campus', even as 'green curriculum'. As a result of the increasing awareness on sustainability and environmental concerns, universities are now a part of environmental sustainability not only through research but also through improving their campus infrastructure into a more environment-friendly setting as well as updating their curricula to cover courses on the environment and sustainability. Today, over 300 universities from all over the world are committed to Higher Education Sustainability Initiative (HESI) which encourages sustainable development activities with partnerships of several parties of the United Nations (Sustainable Development Goals Knowledge Platform, 2019). Hence, the universities are not only concerned with the educational quality but also aim at gaining a competitive advantage through creating a more 'green' campus environment for their students. It should be noted that investing in sustainability holds the potential to generate additional benefits for the universities in terms of significant cost reductions in the long-term.

A growing interest in environmental issues has led to a research stream dedicated to sustainability in universities. A vast amount of research has been produced, especially after 2000 on the discussion of how to institutionalize greening of the university campuses, as well as how to evaluate and compare the universities in terms of 'greening' activities. Nevertheless, several institutions such as UI GreenMetric publish sustainability reports for universities, aiming at ranking world universities for their activities related to green campus and sustainability (Suwartha and Sari, 2013). The assessment tools of this ranking system have been updated every year since its introduction, which motivates universities to adopt sustainability practices in their campus management. Besides, the UI GreenMetric data set itself has been a subject of various research (see Shi and Lai, 2013; Lauder et al. 2015; Parvez and Agrawal, 2019 for such examples).

Although there is a vast amount of research on green universities (see Section 2 for an extensive review), the role of environmental practices in explaining the academic performance of the universities is yet to be investigated. Accordingly, the objective of this research to link environmental sustainability efforts to the academic performance of the universities using a comprehensive data set from different sources. By doing so, the current paper identifies which dimensions of environmental sustainability have a reflection on academic performance. Besides, the influence of country-level environmental practices on the aforementioned relationship is also investigated. Using the university rankings from four well-known academic ranking systems,- namely as Academic Ranking of World Universities (ARWU), QS World University Ranking (QS), Times Higher Education World University Rankings (THE) and National Taiwan University Ranking (NTU) - the current research empirically investigates whether sustainability practices of the universities which are proxied by UI GreenMetric (GM) score explain their academic performance. The research presents the first time attempt to relate $G M$ rankings to the academic rankings, and the findings are expected to fill the gap in the literature by providing valuable insights on promoting green policies of the universities.

In the scope of the current research, a set of models has been set up to reveal the relationship of green practices of the universities with their academic performance. Specifically, the models test (i) whether the GM scores relate to the academic performances of universities, (ii) whether the relationship (if it exists) is valid when the academic scores are aggregated to a composite score, (iii) whether the relationship (if it exists) is contingent upon the scores of environmental performance at country level and (iv) whether the relationship (if it exists) holds for out-of-sample predictions. The relationship is tested using both total scores and sub-dimensions of GM. Moreover, an aggregation scheme for 
academic performance scores from different systems is proposed to test the relationship with composite scores.

The empirical findings indicate that attaining higher scores at $G M$ evaluations has a reflection on the academic scores for the majority of the academic ranking systems. Moreover, sub-dimensions of $U I$ GreenMetric also provide significance in explaining the academic performances of the universities. Further analysis suggests that the environmental performance of the country where the university is located moderate the relationship between university sustainability and academic performance. Overall, the findings indicate that 'being green' has a reflection on university rankings, and the results unveil the 'greening' activities as a competitive advantage for universities in terms of attaining higher ranks in academic ranking systems. As a first attempt to empirically show the relationship between $U I$ GreenMetric and academic scores from well-known academic ranking systems, the findings of this research support the idea that sustainability can be considered as another dimension in evaluating the university success and should be included in ranking systems' evaluation criteria in a more systematic way as indicated by Lukman et al. (2009).

The current paper is organized as follows. Section 2 reviews the previous research on sustainable development in higher education institutions within the scope of the greening of the universities. Section 3 describes the data sets and methodological approaches. In Section 4, the main findings and the results of additional analyses are presented. Section 5 discusses the implications of the empirical results and concludes the paper.

\section{Sustainable Development Research on Green Universities}

The research on green universities is within the scope of Sustainable Development (SD) research. The activities pursued by higher education institutions to provide a greener campus or infrastructure can be seen as steps to attain sustainable development to address rising environmental concerns such as climate change and air pollution. There is a growing body of literature dedicated to sustainable development strategies in the higher education context, emphasizing the importance of greening of the universities. This section discusses prior research with a focus on campus sustainability strategies, evaluation, measurement, and reporting of sustainability and the green curricula.

\subsection{Campus Sustainability Strategies}

Early research on campus sustainability attempts to identify how to institutionalize green practices in universities. The scholars emphasize the necessity of university-wide policy development and suggest to follow out systematic approaches to transform university campuses into environmental-friendly areas. In one of the earlier papers on campus sustainability, Sharp (2002) provides a conceptual framework on policymaking for environmental sustainability. With different examples from world universities, Sharp (2002) discusses some bullet points in achieving organizational change to institutionalize the greening within the university context. Koester et al. (2006) elucidate the campus sustainability issue with a comprehensive approach from an ongoing real-world case at Ball State University. The research presents a systematic approach on campus transformation based on tracking the history, evaluating the progress, modifying the approach, and continually refocusing the effort. In a similar vein, Alshuwaikhat and Abubakar (2008) provide insights into Energy Management System (EMS) implementations for university campuses. They also propose a generalized framework on how to achieve campus sustainability.

Following the discussions on strategy development, the campus sustainability issue has been dealt with at the university level with more specialized applications for several universities located in different parts of the world. Within this scope, one of the earliest attempts is the research conducted by Venetoulis (2001) that measures the ecological footprint for the University of Redlands, USA and 
aims at identifying what makes a green campus, analyzing the current and potential strategies as well as determining the key criteria on the greening of the campuses. Some other examples of specialized research from different countries include:

- Savely et al. (2007)'s model for the Environmental Management System (EMS) implementation at U.S. universities.

- Clark and Kouri (2009)'s discussion of campus environmental management practices in different countries worldwide (the UK, USA, Netherlands, Germany and Mexico);

- Lukman et al. (2009)'s Life Cycle Assessment in University of Maribor, Slovenia;

- Hooi et al. (2012)'s exploratory study resulting in their 3A model (Awareness, Acceptance, and Assimilation) in Malaysian universities;

- Finlay and Massey (2012)'s research examining the potential strategies to create ecological campuses from the perspective of the eco-city framework for North American Universities;

- Jabbour et al. (2013)'s research on assessing environmental management practices of Brazilian Business Schools;

- Geng et al. (2013)'s case study on efforts of Shenyang University in China;

- Yuan et al. (2013)'s research for Chinese Universities;

- Castro and Jabbour (2013)'s evaluation of sustainability in an Indian university using Alshuwaikhat and Abubakar (2008)'s defined variables;

- Tan et al. (2014)'s research on the development of green campuses in China;

- Deus et al. (2016)'s analysis of mission statements in terms of sustainability in Brazil;

- Massimo et al. (2016)'s case study at Mediterranea University, Italy;

- Rwelamila and Purushottam (2016)'s work on strategic project management as a tool to improve campus sustainability in African universities;

- Meiboudi et al. (2017)'s study to develop sustainability criteria for Iranian universities;

- Schmitt and Palm (2018)'s review of sustainability at German universities and case study at Hamburg University.

Throughout the years, the campus sustainability research has evolved from developing strategies to more actively elaborated cases at larger scales. Contemporary examples include research by Peng et al. (2018) and Abu Qdais et al. (2019). Peng et al. (2018) present the details of how a sustainable rainwater utilization and water circulation model has been designed in Peiyang Campus of Tianjin University in China. The outcomes of the new design have been quantitatively evaluated through effect analysis. In a recent research, Abu Qdais et al. (2019) elaborate the action-oriented strategy of greening Jordan University of Science and Technology campus to transform it into a resource-efficient and low-carbon environment, which in turn provide positive effects on electricity, water and fuel consumption of the campus.

Another recent aspect of greening strategies of the university campuses is the concept of Green Offices (GO) introduced as means of green campus management. Aiming at advising and reporting on the sustainability activities, as well as increasing the awareness among students and university staff, Green Offices are also of interest in academic research. Within this context, Adomßent et al. (2019) propose a GO Modelling frame that identifies what sustainability office on campus should look like. Similarly, Leal Filho et al. (2019) point out the importance of the Green and Sustainability Offices' roles in promoting the sustainability activities in university campuses through reporting on a survey conducted in 70 Higher Education Institutions. This research outlines specific aspects of offices' operations and the difficulties related to their activities. 


\subsection{Evaluation, Measurement, and Reporting of Sustainability in Universities}

As well as pursuing sustainability practices in university campuses, evaluating, measuring, and reporting of the outcomes are also crucial and of interest to several studies. Alonso-Almeida et al. (2015) emphasize the importance of reporting sustainability by analyzing the current situation and providing future perspectives, which include both qualitative and quantitative methods by stating, " $a$ sound sustainable development vision requires clear reporting to inform the HEI stakeholders of the benefits of sustainable development". Several other studies discuss the importance of the assessment and reporting to success in sustainable development strategies of the higher education institutions. A survey study that is applied to 70 higher education institutions by Lozano et al. (2015) reveals that although there is a strong link between sustainable development commitment and implementation, the efforts or measures have not been fully integrated into institutional strategies. Inspired by the findings of the survey, Berzosa et al. (2017) provide a comprehensive comparative analysis for different tools to assess sustainability. Four different tools are compared in a single university, concluding that "maximum score for one tool does not assure a good score in the others".

Although Berzosa et al. (2017)'s findings provide valuable insights, it is not a straightforward task to fit the measurement of sustainability to a universal standardization. However, there have been recent attempts to measure the sustainable development or greening levels of the universities. For instance, Gómez et al. (2015) propose an adaptive model to assess the level of sustainability in higher education institutions based on earlier case studies and international declarations. Similarly, Hajrasouliha (2017) develops a campus score based on three attributes (urbanism, greenness, and campus living) and calculates the scores for US universities. Meiboudi et al. (2018) propose a rating model for the greening level of the schools in Iran. Furthermore, Zhao and Zou (2018) develop University Greenness Index (UGI) for Chinese universities.

As being one of the well-known ranking systems, UI GreenMetric has been introduced by the University of Indonesia (UI) in 2010 and acknowledged by the academic literature with the publication by Suwartha and Sari (2013). Also, other ranking systems have been developed to compare universities in terms of sustainability such as Sustainability Tracking, Assessment \& Rating System (STARS), the American College \& University Presidents' Climate Commitment (ACUPCC), and the College Sustainability Report Card (the Green Report Card). Shi and Lai (2013) propose a new sustainability ranking framework based on the criteria of these three systems. A comparative study by Lauder et al. (2015) also deals with different ranking systems, including UI GreenMetric. Marrone et al. (2018) propose Urban Morphology Index (UMI) as a new parameter for the UI GreenMetric system. At a more national level, Shuqin et al. (2019) propose an evaluation system consists of five criteria covering organization \& management, energy \& resource-saving, friendly environment, campus culture, and social outreach. The proposed system has been analyzed in a case study. Furthermore, the first attempt to propose ranking universities considering all three dimensions (research, education, and environment) has been introduced by Lukman et al. (2010) with a new set of ranking criteria combining several academic and environmental dimensions using Analytic Hierarchy Process (AHP) method. The indicators of the well-known ranking systems have also been subjects of other research in measuring the sustainability levels of universities. For instance, Parvez and Agrawal (2019) qualitatively evaluate 9 HEls in India based on UI GreenMetric and STARS indicators. The findings reveal that only $50 \%$ of the indicators are incorporated, and GreenMetric indicators are found to be in greater relevance for the universities under investigation.

\subsection{Green Curricula}

Higher Education Institutions are expected to contribute to society not only through improving their infrastructure but also creating awareness on sustainability among their graduates. This argument dates back to the United Nations Conference on the Human Environment (also known as the 
Stockholm Conference) by the United Nations Environment Programme (UNEP) in 1972 (Gupta and Singhal, 2017). Therefore, one of the policies in the sustainability framework of higher education institutions is the greening of the curricula, especially after the 2000s. Supporting this argument, one of the main criteria in evaluating the sustainability of the universities is the sustainability education in UI GreenMetric.

Considering the rising awareness on education for sustainable development, several other studies evaluate the curricula of the universities in terms of environment and sustainability-related courses. For instance, Xiong et al. (2013) analyze the status of curricula of Chinese universities for their 'greenness'. While emphasizing United Nation's Education for Sustainable Development (EfSD) program, Wang et al. (2013) acknowledge green curriculum practices as one of the most important attempts in the transformation process. Beynaghi et al. (2016) also discuss future sustainability scenarios for universities. In another research, Stough et al. (2017) present a critical assessment of curricula in attaining effective sustainability education. Dagiliūte et al. (2018) emphasize the importance of student perceptions and commitment to the success of the greening process through data collection at two Lithuanian universities (a non-green and a green).

The integration of sustainability in curricula has been discussed for several academic disciplines. Quantitative and qualitative research methods have been utilized at different universities to evaluate the current status and future potentials of the curricula in terms of the integration of sustainable development to current curricula. Several recent studies attempt to identify how sustainability educations can be integrated into different disciplines. For example, Gupta and Singhal (2017) propose a framework for incorporating sustainability in business schools' curricula. Thürer et al. (2018) focus on engineering curricula with a systematic review of the scientific literature resulting in 12 future research questions to be addressed in engineering curriculum design. Ramanujan et al. (2019) focus on engineering curricula and emphasize the use of guided discovery instruction to teach environmental sustainability in a field study at Purdue University mechanical engineering undergraduate program. Similarly, Bradley (2019) utilizes a wide range of data collection tools (surveys, interviews, keyword searches) and conducts field research at Alliance University for integrating sustainable development into the economics curriculum.

\section{Methods}

To test the relationship between 'being green' and academic performance, a broad data collection process that involves five different university ranking systems has been carried out. Of those, $\mathrm{UI}$ GreenMetric World University Ranking (GM) is the one that measures the performance of the universities for green campus and sustainability activities. Regarding academic performance, the data are collected from four well-known university ranking systems, namely Academic Ranking of World Universities (ARWU), QS World University Ranking (QS Ranking), Times Higher Education World University Rankings (THE Ranking) and National Taiwan University Ranking (NTU Ranking). The sample includes all universities which have both UI GreenMetric and at least one academic performance score provided by four ranking systems in 2017. Table 1 summarizes the number of universities included in each ranking system with the number of factors considered in their methodologies.

Table 1. Ranking Systems and Number of Universities

\begin{tabular}{ccc}
\hline Ranking System & \# of Universities (2017) & \# of Factors \\
\hline GM & 617 & 6 \\
ARWU & 500 & 6 \\
QS & 400 & 6 \\
THE & 601 & 5
\end{tabular}


Below, brief information about the ranking systems, including UI GreenMetric and their evaluation criteria, are provided.

\subsection{UI GreenMetric World University Ranking (GM)}

The UI GreenMetric university ranking system aims at ranking world universities for their activities related to green campus and sustainability (UI GreenMetric, 2019). The ranking was introduced by the University of Indonesia (UI) in 2010. The evaluations are based on the annual survey data collected from universities all over the world. The rankings are published every December via their web site relying on the data provided by the universities between May and October. The sub-dimensions, their weights, and the indicators used within the scope of each sub-dimension (extracted from the UI GreenMetric web site) are provided in Table 2. A score in each of the given sub-dimension is published together with a weighted average score calculated based on the given weights. Scores of each subdimension are figured relying on numerical records obtained from a survey which mainly includes counts of things or responses on a scale (UI GreenMetric Methodology, 2019). It should be noted that Education and Research (ED) scores refer to the efforts to create awareness on sustainability, such as having sustainability courses in the curricula or publishing research on sustainability or the environment.

Table 2. UI GreenMetric Sub-dimensions

\begin{tabular}{|c|c|c|c|}
\hline & Factors & Weights (\%) & Indicators \\
\hline 1 & $\begin{array}{l}\text { Setting and } \\
\text { Infrastructure (SI) }\end{array}$ & 15 & $\begin{array}{l}\text { The ratio of open space area towards the total area, Area on } \\
\text { campus covered in forest, Area on campus covered in planted } \\
\text { vegetation, Area on campus for water absorbance, The total } \\
\text { open space area divided by total campus population, } \\
\text { University budget for the sustainable effort. }\end{array}$ \\
\hline 2 & $\begin{array}{l}\text { Energy and Climate } \\
\text { Change (EC) }\end{array}$ & 21 & $\begin{array}{l}\text { Energy-efficient appliances usage, Smart Building } \\
\text { implementation, Number of renewable energy sources in } \\
\text { campus, The total electricity usage divided by total campus } \\
\text { population (kWh per person), The ratio of renewable energy } \\
\text { produced towards energy usage, Elements of green building } \\
\text { implementation as reflected in all construction and renovation } \\
\text { policy, Greenhouse gas emission reductions program, The ratio } \\
\text { of total carbon footprint divided to campus population. }\end{array}$ \\
\hline 3 & Waste (WS) & 18 & $\begin{array}{l}\text { Recycling program for university waste, Program to reduce the } \\
\text { use of paper and plastic in campus, Organic waste treatment, } \\
\text { Inorganic waste treatment, Toxic waste handled, Sewerage } \\
\text { disposal. }\end{array}$ \\
\hline 4 & Water (WR) & 10 & $\begin{array}{l}\text { Water conservation program implementation, Water recycling } \\
\text { program implementation, The use of water-efficient } \\
\text { appliances (water tap, toilet flush, etc.), Treated water } \\
\text { consumed. }\end{array}$ \\
\hline 5 & Transportation (TR) & 18 & $\begin{array}{l}\text { Total number of vehicles (cars and motorcycles) divided by } \\
\text { total campus population, Shuttle service, Zero-Emission } \\
\text { Vehicles (ZEV) policy on campus, The ratio of Zero-Emission } \\
\text { Vehicles (ZEV) divided by total campus population, Ratio of } \\
\text { parking area to total campus area, Transportation program } \\
\text { designed to limit or decrease the parking area on campus for } \\
\text { the last three years (from } 2015 \text { to 2017), Number of } \\
\text { transportation initiatives to decrease private vehicles on } \\
\text { campus, Pedestrian path policy on campus. }\end{array}$ \\
\hline
\end{tabular}


The ratio of sustainability courses to total number of courses/subjects, The ratio of sustainability research funding to total research funding, Number of scholarly publications on environment and sustainability published, Number of scholarly events related to environment and sustainability, Number of student organizations related to environment and sustainability, Existence of a university-run sustainability website, Existence of published sustainability report.

The number of universities included in UI GreenMetric ranking increases every year with inclusions of new universities from different parts of the world. 2017 UI GreenMetric rankings include 617 universities from 80 different countries. The leading country is the United States of America, with 61 universities in 2017 rankings. The shares of different world regions based on the number of universities in UI GreenMetric rankings are given in Figure 1. The majority of the universities are located in Europe, Far East Asia, and North America.

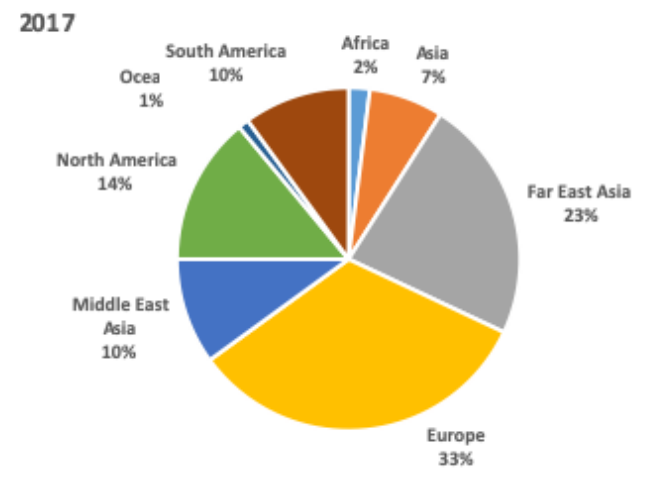

Figure 1. The Shares of Regions in Green Metric Rankings

\subsection{Academic Ranking of World Universities (ARWU)}

Academic Ranking of World Universities (ARWU) is an academic ranking system of world universities firstly introduced by the Center for World-Class Universities (CWCU) at the Graduate School of Education of Shanghai Jiao Tong University (SJTU) in 2003 (Shanghai Ranking, 2019). Since 2009, the ranking activity has been pursued by an independent organization (ShanghaiRanking Consultancy), which is currently known as ShanghaiRanking. This system is based on six sub-dimensions listed in Table 3 with their corresponding weights. The methodology relies on the weighted average of the subdimension scores. The rankings are published annually via its web site.

Table 3. ARWU Ranking Sub-dimensions

\begin{tabular}{llc}
\hline & \multicolumn{1}{c}{ Factors } & Weights (\%) \\
\hline $\mathbf{1}$ & Alumni of an institution winning Nobel Prizes and Fields Medals (Alumni) & 10 \\
$\mathbf{2}$ & The staff of an institution winning Nobel Prizes and Fields Medals (Award) & 20 \\
$\mathbf{3}$ & Highly cited researchers in 21 broad subject categories (HiCi) & 20 \\
$\mathbf{4}$ & Papers published in Nature and Science (N\&S) & 20 \\
$\mathbf{5}$ & Papers indexed in Science Citation Index (PUB) & 20 \\
$\mathbf{6}$ & Per capita academic performance of an institution (PCP) & 10 \\
\hline
\end{tabular}




\subsection{QS World University Ranking (QS)}

QS University ranking was introduced by Quacquarelli Symonds (QS) in 2004. During 2004-2009 it has been pursued in cooperation with Times Higher Education. Currently, the rankings are published independently for each year via its web site (Quacquarelli Symonds, 2019). The sub-dimensions included in the QS system and the weight of each factor are provided in Table 4 . The factor scores and weighted average scores of all universities in the system are publicly available.

Table 4. QS Ranking Sub-dimensions

\begin{tabular}{llc}
\hline & \multicolumn{1}{c}{ Factors } & Weights (\%) \\
\hline $\mathbf{1}$ & Academic Reputation & 40 \\
$\mathbf{2}$ & Employer Reputation & 10 \\
$\mathbf{3}$ & Faculty/Student Ratio & 20 \\
$\mathbf{4}$ & International Faculty Ratio & 5 \\
$\mathbf{5}$ & International Student Ratio & 5 \\
$\mathbf{6}$ & Citations per faculty & 20 \\
\hline
\end{tabular}

\subsection{Times Higher Education World University Rankings (THE)}

Times Higher Education (THE) university ranking is one of the most well-known academic rankings of world universities. The factor set presented in Table 5 takes into both teaching and research performances into account. The system was introduced in 2004 in association with Quacquarelli Symonds. Since 2010, the rankings have been published independently (Times Higher Education, 2019).

Table 5. THE Ranking Sub-dimensions

\begin{tabular}{llc}
\hline & \multicolumn{1}{c}{ Factors } & Weights (\%) \\
\hline $\mathbf{1}$ & Teaching-learning environment & 30 \\
$\mathbf{2}$ & Research-volume, income, reputation & 30 \\
$\mathbf{3}$ & Citations-research influence & 30 \\
$\mathbf{4}$ & Industry income-knowledge transfer & 2.5 \\
$\mathbf{5}$ & International outlook-staff, student, research & 7.5 \\
\hline
\end{tabular}

\subsection{National Taiwan University Ranking (NTU)}

National Taiwan University (NTU) Ranking is published with the name of Performance Ranking of Scientific Papers for World Universities and focuses mainly on the research performance of the universities under three main titles as research productivity, research impact and research excellence. Each title consists of different sub-factors listed in Table 6 with the corresponding weights. The system has been introduced in 2007 and published annually since then at NTU's web site (National Taiwan University, 2019). 
Table 6. NTU Ranking Sub-dimensions

\begin{tabular}{|c|c|c|}
\hline Main Factors & Performance Indicators & Weights (\%) \\
\hline \multirow{2}{*}{ Research Productivity } & Number of articles in the last 11 years & 10 \\
\hline & Number of articles in the current year & 15 \\
\hline \multirow{3}{*}{ Research Impact } & Number of citations in the last 11 years & 15 \\
\hline & Number of citations in the last two years & 10 \\
\hline & The average number of citations in the last 11 years & 10 \\
\hline \multirow{3}{*}{ Research Excellence } & h-index of the last two years & 10 \\
\hline & Number of Highly Cited Papers & 15 \\
\hline & Number of articles in the current year in high-impact journals & 15 \\
\hline
\end{tabular}

This research investigates the relationship between the UI GreenMetric (GM) scores and the academic performances of the universities according to four well-known academic ranking systems (described in Section 3), namely as Academic Ranking of World Universities (ARWU), QS World University Ranking (QS), Times Higher Education World University Rankings (THE) and National Taiwan University Ranking (NTU). Several empirical estimations for different samples of universities are employed to provide a comprehensive outlook of the relationship between 'being green' and academic performance. It is worth noting that UI GreenMetric scores and university rankings for the year 2017 are used in all of the estimations.

\subsection{The relationship between UI GreenMetric scores and academic performance of the universities for each academic ranking system}

In the first part of the empirical investigation, the UI GreenMetric scores are separately regressed with the academic performances of the universities provided by ARWU, QS, THE, and NTU. To this aim, the universities that appear both in UI GreenMetric rankings and each of the four academic ranking systems are matched. Therefore, the sample size for each estimation depends on the ranking system under investigation. Table 7 presents the numbers of universities that appear in both datasets as of 2017.

Table 7. The intersection of GM with the Academic Performance Rankings

\begin{tabular}{lc}
\hline Data sets & \# of universities in both data sets \\
\hline GM \& ARWU & 86 \\
GM \& QS & 83 \\
GM \& THE & 117 \\
GM \& NTU & 85 \\
\hline
\end{tabular}

To observe the relationship between UI GreenMetric scores and the academic performances of the universities, the following model is estimated:

$$
A S_{i}=\alpha+\beta G M_{i}+\text { Country }_{c}+\varepsilon_{i}
$$

In Equation 1, $A S_{i}$ corresponds to the academic scores of the university in four different academic ranking systems, namely ARWU, QS, THE, and NTU in 2017. GM $M_{i}$ denotes six different UI GreenMetric sub-scores, namely Setting and Infrastructure (SI), Energy and Climate Change (EC), Waste (WS), Water (WR), Transportation (TR), Education and Research (ED)) and also GreenMetric Total Score (GMTS) of the university in 2017. $\beta$ is the coefficient of UI GreenMetric score, $\alpha$ is the constant term, and $\varepsilon_{i}$ 
denotes the error terms of the estimation. Another important factor that should be taken into account is the characteristics of the country where the university of located. It is reasonable to expect that some of the countries have better financial position (e.g. GDP per capita) and education history than others. For example, universities located in United States dominates the top 10 position in almost all of the different university rankings. Therefore, country-specific factors should be incorporated into the estimation model to avoid omitted variable bias. To control for the unobserved country fixed effects, country dummies (Countryc) are included in all of the estimations. Heteroscedasticity-robust standard errors are reported to account for the variance heterogeneity.

\section{Results and Findings}

\subsection{Main Results}

Table 8 presents the results regarding the relationship between UI GreenMetric Total Score (GMTS) and academic performance scores provided by four different academic performance ranking systems. Having a positive coefficient, GM provides significance in 3 out of 4 academic ranking systems (ARWU, $Q S$, and THE) in explaining the academic performances. In other words, the greater portion of the variation in the university academic performances is explained by the environmental policies and performance of the universities measured by the UI GreenMetric score. Moreover, the positive coefficient of GMTS suggests that universities with a high score in environmental performance, also have higher scores of academic performances. The only insignificant relationship is observed between GMTS and academic scores provided by NTU. Overall, the findings indicate that attaining higher scores at $G M$ evaluations has a reflection on the academic scores in the majority of the academic ranking systems.

Table 8. Relationship between Academic Score and GM Total Score

\begin{tabular}{lllll}
\hline & ARWU & QS & THE & NTU \\
GM Total Score (GMTS) & $0.698^{* *}$ & $0.737^{* * *}$ & $0.290^{* *}$ & 0.217 \\
& $(0.284)$ & $(0.223)$ & $(0.128)$ & $(0.131)$ \\
Constant & -3.202 & -2.507 & 1.257 & $2.124^{*}$ \\
$\mathrm{R}^{2}$ & $(2.427)$ & $(1.922)$ & $(1.091)$ & $(1.124)$ \\
\# of observations & 0.456 & 0.511 & 0.544 & 0.248 \\
& 86 & 83 & 117 & 85
\end{tabular}

Notes: Country-fixed effects are included in all estimations. Robust standard errors are in parenthesis. ${ }^{* *}, * *$, and $*$ denote the significance at $1 \%, 5 \%$, and $10 \%$ levels, respectively.

As a next step, the relationship between the academic performance of the universities and six subdimensions of the GMTS (see Table 2 for details) is tested. This attempt is important to observe how sub-dimensions of UI GreenMetric provide significance in explaining the academic performance of the universities. The estimation results are presented in Table 9.

Table 9. Relationship between Academic Scores and GM Factors

\begin{tabular}{lllll}
\hline \multicolumn{1}{c}{ ARWU } & \multicolumn{1}{c}{ QS } & \multicolumn{1}{c}{ THE } & \multicolumn{1}{c}{ NTU } \\
\hline \multicolumn{2}{l}{ Panel A. Setting and Infrastructure $(S I)$} & & & \\
SI & 0.042 & $0.357^{* *}$ & 0.166 & 0.084 \\
& $(0.214)$ & $(0.156)$ & $(0.102)$ & $(0.085)$ \\
Constant & $2.508^{*}$ & 1.465 & $2.646^{* * *}$ & $3.430^{* * *}$ \\
& $(1.395)$ & $(1.030)$ & $(0.662)$ & $(0.553)$ \\
$\mathrm{R}^{2}$ & 0.388 & 0.428 & 0.535 & 0.212
\end{tabular}


Panel B. Energy and Climate Change (EC)

\begin{tabular}{|c|c|c|c|c|}
\hline \multirow[t]{2}{*}{$E C$} & 0.169 & $0.208^{*}$ & 0.006 & 0.043 \\
\hline & $(0.124)$ & $(0.108)$ & $(0.070)$ & $(0.069)$ \\
\hline \multirow[t]{2}{*}{ Constant } & $1.636^{*}$ & $2.409 * * *$ & $3.696 * * *$ & $3.693 * * *$ \\
\hline & $(0.840)$ & $(0.744)$ & $(0.477)$ & $(0.470)$ \\
\hline $\mathrm{R}^{2}$ & 0.402 & 0.405 & 0.520 & 0.203 \\
\hline \multicolumn{5}{|c|}{ Panel C. Waste (WS) } \\
\hline \multirow[t]{2}{*}{ WS } & $0.735 * * *$ & $0.528 * * *$ & $0.240 * *$ & $0.231 * *$ \\
\hline & $(0.242)$ & $(0.178)$ & $(0.113)$ & $(0.101)$ \\
\hline \multirow[t]{2}{*}{ Constant } & -2.524 & 0.021 & $2.006 * *$ & $2.315 * * *$ \\
\hline & $(1.744)$ & (1.294) & $(0.820)$ & $(0.731)$ \\
\hline$R^{2}$ & 0.484 & 0.477 & 0.540 & 0.275 \\
\hline \multicolumn{5}{|c|}{ Panel D. Water (WR) } \\
\hline \multirow[t]{2}{*}{$W R$} & $0.202 * *$ & $0.194 *$ & $0.112 * *$ & 0.046 \\
\hline & $(0.091)$ & $(0.098)$ & $(0.049)$ & $(0.046)$ \\
\hline \multirow[t]{2}{*}{ Constant } & $1.519 * * *$ & $2.610 * * *$ & $3.041 * * *$ & $3.696 * * *$ \\
\hline & $(0.561)$ & $(0.623)$ & $(0.307)$ & $(0.286)$ \\
\hline $\mathrm{R}^{2}$ & 0.433 & 0.451 & 0.546 & 0.221 \\
\hline \multicolumn{5}{|c|}{ Panel E. Transportation (TR) } \\
\hline \multirow[t]{2}{*}{$T R$} & $0.687 * * *$ & $0.512 * *$ & $0.298 * *$ & 0.149 \\
\hline & $(0.200)$ & $(0.240)$ & $(0.115)$ & (0.099) \\
\hline \multirow[t]{2}{*}{ Constant } & -1.924 & 0.314 & $1.701 * *$ & $2.967 * * *$ \\
\hline & $(1.362)$ & $(1.657)$ & $(0.782)$ & $(0.678)$ \\
\hline $\mathrm{R}^{2}$ & 0.504 & 0.466 & 0.560 & 0.252 \\
\hline \multicolumn{5}{|c|}{ Panel F. Education and Research (ED) } \\
\hline \multirow[t]{2}{*}{$E D$} & 0.040 & 0.123 & 0.040 & -0.061 \\
\hline & $(0.172)$ & $(0.128)$ & $(0.073)$ & $(0.067)$ \\
\hline \multirow[t]{2}{*}{ Constant } & $2.520 * *$ & $3.028 * * *$ & $3.475^{* * *}$ & $4.390 * * *$ \\
\hline & $(1.121)$ & $(0.846)$ & $(0.477)$ & $(0.438)$ \\
\hline$R^{2}$ & 0.388 & 0.386 & 0.522 & 0.209 \\
\hline \# of observations & 86 & 83 & 117 & 85 \\
\hline
\end{tabular}

Notes: Country-fixed effects are included in all estimations. Robust standard errors are in parenthesis. ***, **, and ${ }^{*}$ denote the significance at 1\%, 5\%, and $10 \%$ levels, respectively.

The results in Table 9 provides several interesting insights. First, Waste (WS) dimension of UI GreenMetric, which is associated with the installation of sustainable waste management systems throughout the campuses, holds a strong positive relationship with the academic scores of all four academic ranking systems. That is followed by Transportation (TR) and Water (WR), which have significant relationships with academic ranking scores of $A R W U, Q S$, and THE. However, Energy and Climate Change (EC) and Setting and Infrastructure (SI) dimensions are only significant in explaining the academic scores provided by QS. Interestingly, the coefficient of Education and Research (ED) dimension of UI GreenMetric is not statistically significant at the conventional levels in explaining the scores provided by academic performance ranking systems. Specifically, the $p$-values of $E D$ ranges from 0.342 (QS ranking) to 0.815 (ARWU ranking) which indicates a low level of association between ED and 
academic scores. This result reveals that sustainability education is not a function of the overall academic performance of the universities. One possible reason for this relationship is that these universities have a well-established academic curriculum, and it may not be straightforward for them to adopt 'green' courses into their program in the short-term. However, one might expect a significant relationship between 'green' education and academic performance in the long-term, which is beyond the scope of this study.

From the perspective of the academic ranking systems, it is observed that the majority of the $U I$ GreenMetric dimensions provide significance in explaining the $Q S$ scores, which is followed by THE and $A R W U$ scores. On the other hand, no significant relationship between the scores provided by NTU and UI GreenMetric dimensions except the Waste (WS) dimension is found. Moreover, estimations regarding the NTU ranking system have a significantly lower R squared values (ranges from 0.203 to 0.275) than those of other estimations, which indicates a weaker association of NTU academic score with the UI GreenMetric scores. Therefore, it can be concluded that the NTU ranking system differs from the other major ranking systems in terms of the reflection of university sustainability. Since the main focus of the NTU ranking system is on research outcomes such as published articles and citations, it is not surprising to observe an insignificant relationship between NTU score and UI GreenMetric sustainability score.

\subsection{The relationship between UI GreenMetric scores and aggregated academic performance}

Although investigating the link between $\mathrm{UI}$ GreenMetric and academic performance scores published by four well-known systems provides important implications, the issue still requires clarification since academic performance data sets are not homogenous, and each ranking system uses different performance indicators as it is discussed before. Also, the results in Table 9 suggest that previous findings are quite sensitive to the academic ranking system selection. More importantly, there is no consensus among the academics on which factors should be considered in evaluating the university performance and which performance ranking system performs better in measuring the true performance of the universities. To overcome this controversy, an aggregation scheme of the different academic performance rankings is proposed to gain a better understanding of the aforementioned relationship. Moreover, using an aggregated academic performance score serves as a robustness check by increasing the sample size to 146 universities with a 'green' score and a composite academic performance score. However, it is not straightforward to attain a composite score since being excluded in any ranking system does not necessarily indicate a poor performance since some universities may not be evaluated or excluded from the list for some specific reasons. Therefore, it may be misleading to add total scores to end up with a composite score, which will lead to a dramatic negative effect on the score of the university, which is not included in a ranking system. On the other hand, it is also unfair to use simple averages because, in this case, a university that is included in a limited number of lists (e.g., in only one) with a high score may dominate a university covered by several lists with relatively low scores. In this scenario, universities that are included in more ranking systems would be punished. To strike a balance, an experimental aggregation scheme is designed that avoids underrating a university that is not included in a ranking system but, at the same time, rewards it, to some extent, if it is included in. The proposed aggregation scheme also appreciates higher ranks since it captures the relative performance of the university regardless of which ranking system has taken into account, and also it serves as a standardized measure that eliminates the concerns regarding the methodological differences among ranking systems. Proposed Aggregated Academic Score (AAS) is formulated as follows:

Let

$U \quad$ Set of universities with at least one score in academic ranking systems

$K \quad$ Set of academic ranking systems 
$s_{i j} \quad$ Score of university $i$ in ranking system $j$

$r_{i j} \quad$ Rank of university $i$ in ranking system $j$

$w_{i} \quad$ Number of times university $i$ is included in different ranking systems divided by four ${ }^{1}$

$$
A A S_{i}=\left(\sum_{\substack{i \in U \\ j \in K}} \frac{s_{i j}}{r_{i j}}\right) \times w_{i}
$$

Using the formula in Equation (2), a single composite academic performance score is obtained, which takes into account the total scores in each system, ranks of the universities, and also the number of times which a university is covered by the ranking systems. Then, the $U I$ GreenMetric dimensions are regressed with the $A A S_{i}$ as follows:

$$
A A S_{i}=\alpha+\beta G M_{i}+\varepsilon_{i}
$$

In Equation 3, $A A S_{i}$ corresponds to the composite academic performance score of university $i$ and $G M_{i}$ is the UI GreenMetric dimensions, including the GMTS of university $i$ as previously defined.

As it is presented in Table 10, there is a significant positive relationship between AAS and GMTS which verify earlier results. Moreover, the majority of the UI GreenMetric dimensions are significant in explaining the Aggregated Academic Score (AAS). Similar to the prior findings, Energy and Climate Change (EC), Waste (WS), Water (WR), and Transportation (TR) have a significant and positive relationship with the academic performance of the universities. On the other hand, Setting and Infrastructure (SI) and Education and Research (ED) do not exert any significance in explaining academic performance. Therefore, it can be concluded that the main results are robust to different considerations of academic performances.

Table 10. Relationship between Aggregated Academic Score and GM Criteria

\begin{tabular}{llllllll}
\hline & GMTS & SI & EC & WS & WR & TR & ED \\
\hline GreenMetric & $2.191^{* * *}$ & 0.406 & $0.696^{* *}$ & $1.793^{* * *}$ & $0.495^{* *}$ & $1.574^{* * *}$ & 0.479 \\
& -0.611 & -0.411 & -0.312 & -0.525 & -0.2 & -0.504 & -0.308 \\
Constant & $-18.046^{* * *}$ & -2.006 & $-4.065^{*}$ & $-12.221^{* * *}$ & $-2.385^{*}$ & $-10.060^{* * *}$ & -2.443 \\
& -5.186 & -2.693 & -2.087 & -3.745 & -1.226 & -3.41 & -1.977 \\
$\mathrm{R}^{2}$ & 0.441 & 0.373 & 0.391 & 0.440 & 0.402 & 0.433 & 0.379 \\
\# of observations & 146 & 146 & 146 & 146 & 146 & 146 & 146 \\
\hline
\end{tabular}

Notes: The dependent variable of the regression models is the Aggregated Academic Score (AAS). Countryfixed effects are included in all estimations. Robust standard errors are in parenthesis. ${ }^{* * *},{ }^{* *}$, and * denote the significance at $1 \%, 5 \%$, and $10 \%$ levels, respectively.

\subsection{The relationship between UI GreenMetric scores and aggregated academic performance under the moderating effect of country-level Environmental Performance Index (EPI)}

Although country fixed effects are controlled in all of the estimations, it does not rule out a possible moderating effect of environmental sustainability at the country level on the relationship between $U I$ GreenMetric scores and academic performance. Since some countries perform better than the others in terms of protection of the environment and environmental awareness, it can be argued that the

\footnotetext{
${ }^{1} w_{i}$ takes values of $0.25,0.50,0.75$ and 1 depending on the coverage of the university.
} 
association between UI GreenMetric scores and academic performances of the universities is stronger in countries with higher environmental performance. To this aim, an interaction term of $\mathrm{UI}$ GreenMetric scores and country-level environmental sustainability, which is proxied by the Environmental Performance Index (EPI), is included in the model. EPI is jointly published by Yale and Columbia Universities in association with World Economic Forum. This index is published bi-annually through its web site ${ }^{2}$ and aims at scoring the countries using several indicators related to environmental policies. The modified regression model is as follows:

$$
A A S_{i}=\alpha+\beta_{1} G M_{i}+\beta_{2} G M_{i} x E P I_{j}+\varepsilon_{i}
$$

In Equation 4, $E P I_{j}$ corresponds to the environmental performance index of country $\mathrm{j}$ in 2017. Other variables are previously defined. A positive coefficient of $G M_{i} x E P I_{j}\left(\beta_{2}\right)$ indicates that higher countrylevel environmental performance reinforces the relationship between 'green' scores and academic performances of the universities.

According to the results presented in Table 11, the country-level environmental performance has a significant moderating effect on the relationship between the majority of the UI GreenMetric dimensions and academic performance. Specifically, the positive impact of Setting and Infrastructure $(S I)$, Energy and Climate Change (EC), Water (WR), Transportation (TR), and Education and Research (ED) dimensions on academic performance is greater in countries with higher environmental performance. The only insignificant relationship is observed for the Waste (WS) dimension. Overall, it is evident that in addition to the university-level environmental policies, country-level environmental awareness and sustainability helps to explain the variation in academic scores across universities through reinforcing the impact of UI GreenMetric scores on academic performance.

Table 11. Moderating Effect of Country-level Environmental Performance (EPI)

\begin{tabular}{llllllll}
\hline & \multicolumn{1}{c}{ GMTS } & \multicolumn{1}{c}{$\boldsymbol{S I}$} & \multicolumn{1}{c}{ EC } & \multicolumn{1}{c}{ WS } & \multicolumn{1}{c}{$\boldsymbol{W R}$} & \multicolumn{1}{c}{ TR } & \multicolumn{1}{c}{ ED } \\
\hline GM & $1.924^{* * *}$ & $0.593^{*}$ & $0.559^{* * *}$ & $1.325^{* * *}$ & $0.590^{* * *}$ & $1.442^{* * *}$ & $0.623^{* *}$ \\
& $(0.479)$ & $(0.307)$ & $(0.209)$ & $(0.318)$ & $(0.179)$ & $(0.411)$ & $(0.249)$ \\
GM x EPI & 0.090 & $0.307^{* * *}$ & $0.196^{* *}$ & 0.054 & $0.248^{* *}$ & $0.261^{* *}$ & $0.207^{* *}$ \\
& $(0.076)$ & $(0.101)$ & $(0.096)$ & $(0.090)$ & $(0.105)$ & $(0.102)$ & $(0.095)$ \\
Constant & $-15.773^{* * *}$ & -3.237 & $-3.136^{* *}$ & $-8.859^{* * *}$ & $-2.973^{* * *}$ & $-9.161^{* * *}$ & $-3.379^{* * *}$ \\
& $(4.018)$ & $(1.985)$ & $(1.365)$ & $(2.218)$ & $(1.052)$ & $(2.731)$ & $(1.560)$ \\
& & & & & & & \\
$\mathrm{R}^{2}$ & 0.124 & 0.031 & 0.041 & 0.095 & 0.097 & 0.115 & 0.045 \\
\# of obs. & 146 & 146 & 146 & 146 & 146 & 146 & 146 \\
\hline
\end{tabular}

Notes: This table presents the impact of country-level environmental performance index on the relationship between the green metrics and aggregate educational score. GM variable corresponds to UI GreenMetric Total Score (GMTS) and six dimensions of GreenMetric. Dependent Variable is Aggregate Academic Score (AAS). Robust standard errors are in parenthesis. ${ }^{* *}, * *$, and $*$ denote the significance at $1 \%, 5 \%$, and $10 \%$ levels, respectively.

\subsection{Out-sample prediction of academic performance with UI GreenMetric scores}

To show the persistence of the relationship between UI GreenMetric scores and academic performance, the predictive power of the baseline model is tested through out-sample predictions. Specifically, the UI GreenMetric Total Score (GMTS) is regressed with the Aggregated Academic Score (AAS) using 2016 data, and then the estimated coefficient of GMTS (from 2016 data) is used to predict the AAS for 2017. Thus, it is possible to demonstrate how much variation in academic scores is explained by UI GreenMetric scores in an out-sample prediction.

\footnotetext{
${ }^{2}$ https://epi.envirocenter.yale.edu/
} 
Before moving on the out-sample predictions, the relationship between AAS and the predicted values of ASS for in-sample estimation for 2017 (Equation 4) in Figure 2. Supporting the prior results, UI GreenMetric scores have a good explanatory power on the academic performance of the universities.

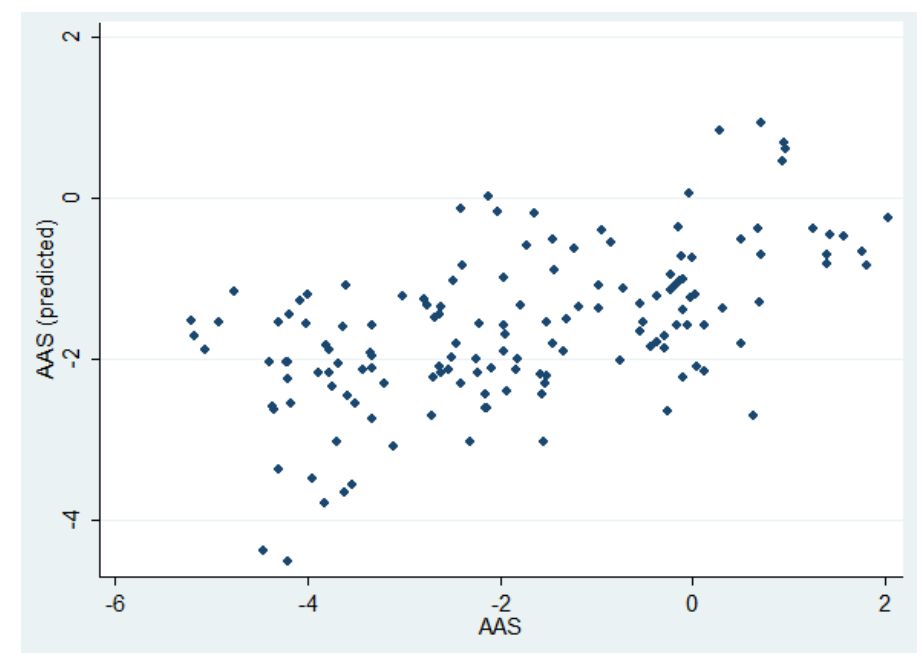

Figure 2. In-sample prediction of Aggregated Academic Score (AAS)

Figure 3 plots actual and predicted AAS for out-sample estimation. It is evident that the UI GreenMetric score has a good predictive ability, even in the out-sample predictions. Therefore, it can be argued that the relationship between $U I$ GreenMetric scores and academic performances of the universities are robust to the different sample period and set of universities.

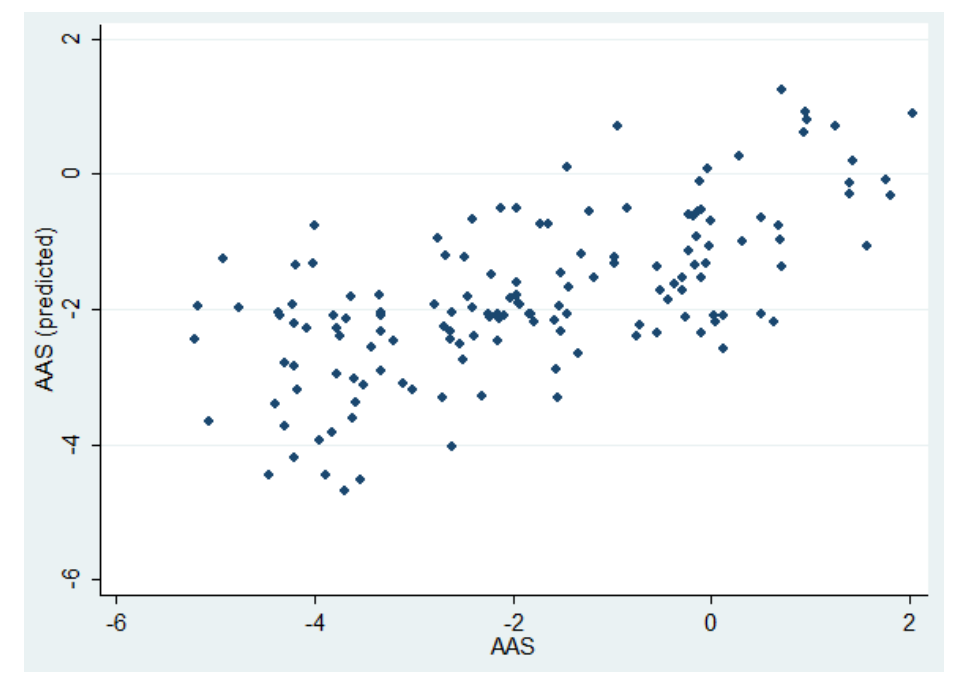

Figure 3. Out-sample prediction of Aggregated Academic Score (AAS)

\subsection{Discussion of the Findings}

Empirical analysis provides evidence that higher scores in environmental performance, measured by UI GreenMetric ranking system, relates to higher scores of academic performances in well-known ranking systems, namely Academic Ranking of World Universities (ARWU), QS World University Ranking (QS) and Times Higher Education World University Rankings (THE). The significant relationship also exists in aggregated academic scores, which takes four ranking systems into account and serves as a composite academic performance index. This result supports the findings of Beynaghi et al. (2016) 
on green universities, which emphasize the importance of measures for greening in evaluating the overall performance of the universities. In addition, the implications of this study align with the findings of Lukman et al. (2010) which propose an integrated approach to assess the performance of universities based on research, education and environmental dimensions. In accordance with the arguments proposed by Geng et al. (2013), the greening of the universities not only provides environmental benefits to the universities but also reinforces the image of the universities that may also translate into higher student satisfaction, productivity and academic performance.

As another important implication of the results, country-level environmental performance, measured by Environmental Performance Index (EPI) has a significant moderating effect on the relationship between 'green' scores and academic performance. The association of Setting and Infrastructure (SI) and Education and Research (ED) sub-dimensions with the scores of the academic ranking systems are highly moderated by the national environmental performance with significant interaction term which indicates that the impact of $S I$ and $E D$ dimensions on academic score significantly depend on the country's Environmental Performance Index (EPI). If the university is located in an environmentally better-performing country, then, $S I$ and $E D$ sub-dimensions have a significant relationship with academic performance. This is important, especially for $E D$ sub-dimension, since it implies that sustainability education and research in a university creates more impact when there is consciousness in the country as a whole. In accordance with the several cases presented in the literature (e. g. Geng et al. 2013; Jabbour et al. 2013; Savely et al. 2007), it is evident that green university initiatives play a key role in linking the sustainable actions and academic performance in the universities.

\section{Conclusions}

Green University is a contemporary concept associated with the implementation of sustainability and environment-friendly strategies to the university campuses, as well as updating the curricula to include courses on environment and sustainability. Different implications of the concept have been discussed with both qualitative and quantitative perspectives in the academic literature. The current research investigates whether green practices at university campuses have a relationship with academic success. Although no causality can be implied, it is verified that green university practices have a reflection in academic rankings, and therefore, higher scores in environmental performance are reflected in the academic performance of the universities. Besides, country-level environmental performance reinforces the positive impact of sustainability on the academic performance of the universities. Out-of-sample predictions reveal that a significant relationship between sustainability and academic performance is not sensitive to the sample composition and time. Such findings reveal the greening of the campuses as one of the tools to establish a competitive advantage for the university. The results support the earlier discussions on the importance of the sustainability policies implemented by university managements. Nevertheless, the sustainability dimension can be accounted for as one of the significant factors to be included in ranking the universities. Moreover, the findings at a sub-dimension level can provide valuable insights for the developers of sustainability metrics for universities.

Over recent years, there is a growing discussion on how sustainable practices enhance the well-being of society. Although being sustainable is not cost-free, putting sustainable practices in force creates long-term value for the economies, corporations, as well as for the universities. Today, many of the universities are under pressure from governments, society, and students to operate sustainably. Importantly, universities usually emphasize social and environmental sustainability as one of their core missions, and they take several actions to enhance the student experience by promoting sustainable practices as well as environmental awareness. However, this process is not straightforward, and policymaker faces significant challenges and costs in converting their campus into a sustainable one. Moreover, this transformation requires considerable support from the top management of the universities, and a significant amount of material and immaterial resources should be directed to 
sustainable practices. Despite the significant challenges to be met, the findings of this paper reveal that it pays to be green from the academic performance perspective. Therefore, it is encouraging for the universities as well as national governments to support green initiatives and to put environmental efforts at the core of their operations. Given that environmental practices become much more important due to concerns related to climate change and $\mathrm{CO}_{2}$ emissions, it is reasonable to expect that society will be much more demanding from the universities in doing sustainable practices.

This paper is not without limitations. First, due to the limited number of universities included in $U I$ GreenMetric, it may not be possible to generalize the results for all of the universities. In addition, there are some other ranking agencies (i.e. Times Higher Education, People \& Planet) which provide university rankings in several sustainability aspects. Incorporating this data will be useful to understand how academic performance relates to different green criteria reported by other agencies. Finally, including university-level control variables (such as university budget, number of students, etc.) into the model will ensure the robustness of the results. This awaits further research. 


\begin{tabular}{|c|c|}
\hline AAS & Aggregated Academic Score \\
\hline ACUPCC & the American College \& University Presidents' Climate Commitment \\
\hline AHP & Analytic Hierarchy Process \\
\hline$A R W U$ & Academic Ranking of World Universities \\
\hline AS & Academic Scores \\
\hline CWCU & Center for World-Class Universities \\
\hline EC & Energy and Climate Change \\
\hline$E D$ & Education and Research \\
\hline EfSD & Education for Sustainable Development \\
\hline EMS & Energy Management System \\
\hline EPI & Environmental Performance Index \\
\hline GM & GreenMetric \\
\hline GMTS & GreenMetric Total Score \\
\hline GO & Green Offices \\
\hline HEls & Higher Education Institutions \\
\hline HESI & Higher Education Sustainability Initiative \\
\hline $\mathrm{HiCi}$ & Highly Cited \\
\hline$N \& S$ & Nature and Science \\
\hline NTU & National Taiwan University \\
\hline$P C P$ & Per Capita Performance \\
\hline$P \cup B$ & Papers indexed in Science Citation Index ( as an ARWU ranking sub-dimension) \\
\hline QS & Quacquarelli Symonds \\
\hline$S D$ & Sustainable Development \\
\hline$S I$ & Setting and Infrastructure \\
\hline SJTU & Shanghai Jiao Tong University \\
\hline STARS & Sustainability Tracking, Assessment \& Rating System \\
\hline$T H E$ & Times Higher Education \\
\hline$T R$ & Transportation \\
\hline$U G I$ & University Greenness Index \\
\hline$U I$ & University of Indonesia (Universitas Indonesia) \\
\hline UMI & Urban Morphology Index \\
\hline$U N$ & United Nations \\
\hline US & United States \\
\hline$W R$ & Water \\
\hline WS & Waste \\
\hline UNEP & United Nations Environment Programme \\
\hline ZEV & Zero-Emission Vehicles \\
\hline
\end{tabular}




\section{References}

Abu Qdais, H., Saadeh, O., Al-Widyan, M., Al-tal, R., Abu-Dalo, M., 2019. Environmental sustainability features in large university campuses: Jordan University of Science and Technology (JUST) as a model of green university. Int. J. Sustain. High. Educ. 20 (2), 214-228. https://doi.org/10.1108/IJSHE-06-2018-0102.

Adomßent, M., Grahl, A., Spira, F., 2019. Putting sustainable campuses into force: Empowering students, staff and academics by the self-efficacy Green Office Model. Int. J. Sustain. High. Educ. 20 (3), 470-481. https://doi.org/10.1108/IJSHE-02-2019-0072.

Alonso-Almeida, M., Marimon, F., Casani, F., Rodriguez-Pomeda, J., 2015. Diffusion of sustainability reporting in universities: current situation and future perspectives. J. Clean. Prod. 106, 144-154. https://doi.org/10.1016/j.jclepro.2014.02.008.

Alshuwaikhat, H.M., Abubakar, I., 2008. An integrated approach to achieving campus sustainability: assessment of the current campus environmental management practices. J. Clean. Prod. 16, 17771785. https://doi.org/10.1016/j.jclepro.2007.12.002.

Berzosa, A., Bernaldo, M.O., Fernández-Sanchez, G., 2017. Sustainability assessment tools for higher education: An empirical comparative analysis. J. Clean. Prod. 161, 812-820. https://doi.org/10.1016/j.jclepro.2017.05.194.

Beynaghi, A., Trencher, G., Moztarzadeh, F., Mozafari, M., Maknoon, R., Leal Filho, W., 2016. Future sustainability scenarios for universities: Moving beyond the United Nations Decade of Education for Sustainable Development. J. Clean. Prod. 112, 3464-3478. https://doi.org/10.1016/j.jclepro.2015.10.117.

Bradley, P., 2019. Integrating sustainable development into economics curriculum: A case study analysis and sector wide survey of barriers. J. Clean. Prod. 209, 333-352. https://doi.org/10.1016/i.jclepro.2018.10.184.

Castro, R., Jabbour, C.J.C., 2013. Evaluating sustainability of an Indian university. J. Clean. Prod. 61, 5458. https://doi.org/10.1016/j.jclepro.2013.02.033.

Clarke, A., Kouri, R. 2009. Choosing an appropriate university or college environmental management system. J. Clean. Prod. 17(11), 971-984. https://doi.org/10.1016/i.jclepro.2009.02.019.

Dagiliūtè, R., Liobikienè, G., Minelgaitè, A., 2018. Sustainability at universities: Students' perceptions from Green and Non-Green universities. J. Clean. Prod. 181, 473-482. https://doi.org/10.1016/j.jclepro.2018.01.213.

Deus, R.M., Battistelle, R.A.G., Silva, G.H.R.D., 2016. Sustainability insights from the mission statements of leading Brazilian Universities. Int. J. Educ. Manag. 30 (3), 403-415. https://doi.org/10.1108/IJEM05-2014-0065.

Finlay, J., Massey, J., 2012. Eco-campus: applying the ecocity model to develop green university and college campuses. Int. J. Sustain. High. Educ. 13 (2), 150-165. https://doi.org/10.1108/14676371211211836.

Geng, Y., Liu, K., Xue, B., Fujita, T., 2013. Creating a "green university" in China: a case of Shenyang University. J. Clean. Prod. 61, 13-19. https://doi.org/10.1016/j.jclepro.2012.07.013.

Gómez, F.U., Sáez-Navarrete, C., Lioi, S.R., Marzuca, V.I., 2015. Adaptable model for assessing sustainability in higher education. J. Clean. Prod. 107, 475-485. https://doi.org/10.1016/i.jclepro.2014.07.047.

Gupta, H., Singhal, N., 2017. Framework for embedding sustainability in business schools: a review. Vision. 21 (2), 195-203. https://doi.org/10.1177/0972262917700993. 
Hajrasouliha, A., 2017. Campus score: Measuring university campus qualities. Landscape Urban Plan. 158, 166-176. https://doi.org/10.1016/j.landurbplan.2016.10.007.

Hooi, K.K., Hassan, F., Mat, M.C., 2012. An exploratory study of readiness and development of green university framework in Malaysia. Procd. Soc. Behv. 50, 525-536. https://doi.org/10.1016/i.sbspro.2012.08.056.

Jabbour, C.J.C., Sarkis, J., de Sousa Jabbour, A.B.L., Govindan, K., 2013. Understanding the process of greening of Brazilian business schools. J. Clean. Prod. 61, 25-35. https://doi.org/10.1016/i.jclepro.2013.05.001.

Koester, R.J., Eflin, J., Vann, J., 2006. Greening of the campus: a whole-systems approach. J. Clean. Prod. 14, 769-779. https://doi.org/10.1016/i.jclepro.2005.11.055.

Lauder, A., Sari, R.F., Suwartha, N., Tjahjono, G., 2015. Critical review of a global campus sustainability ranking: GreenMetric. J. Clean. Prod. 108, 852-863. https://doi.org/10.1016/j.jclepro.2015.02.080.

Leal Filho, W., Will, M., Salvia, A.L., Adomßent, M., Grahl, A., Spira, F., 2019. The role of green and sustainability offices in fostering sustainability efforts at higher education institutions. J. Clean. Prod. 232, 1394-1401. https://doi.org/10.1016/j.jclepro.2019.05.273.

Lozano, R., Ceulemans, K., Alonso-Almeida, M., Huisingh, D., Lozano, F. J., Waas, T., ... \& Hugé, J., 2015. A review of commitment and implementation of sustainable development in higher education: results from a worldwide survey. J. Clean. Prod. 108, 1-18. https://doi.org/10.1016/i.jclepro.2014.09.048.

Lukman, R., Krajnc, D., Glavič, P., 2010. University ranking using research, educational and environmental indicators. J. Clean. Prod. 18 (7), 619-628. https://doi.org/10.1016/i.jclepro.2009.09.015.

Lukman, R., Tiwary, A., Azapagic, A., 2009. Towards greening a university campus: The case of the University of Maribor, Slovenia. Resour. Conserv. Recy. 53, 639-644. https://doi.org/10.1016/j.resconrec.2009.04.014.

Marrone, P., Orsini, F., Asdrubali, F., Guattari, C., 2018. Environmental performance of universities: Proposal for implementing campus urban morphology as an evaluation parameter in Green Metric. Sustain. Cities Soc. 42, 226-239. https://doi.org/10.1016/j.scs.2018.07.012.

Massimo, D.E., Fragomeni, C., Malerba, A., Musolino, M., 2016. Valuation supports green university: case action at Mediterranea campus in Reggio Calabria. Procd. Soc. Behv. 223, 17-24. https://doi.org/10.1016/i.sbspro.2016.05.278.

Meiboudi, H., Lahijanian, A., Shobeiri, S.M., Jozi, S.A., Azizinezhad, R., 2017. Development and validation of sustainability criteria of administrative green schools in Iran. J. Environ. Manage. 197, 605-609. https://doi.org/10.1016/i.jenvman.2017.04.045.

Meiboudi, H., Lahijanian, A., Shobeiri, S.M., Jozi, S.A., Azizinezhad, R., 2018. Development of a new rating system for existing green schools in Iran. J. Clean. Prod. 188, 136-143. https://doi.org/10.1016/j.jclepro.2018.03.283.

National Taiwan University, 2019. Performance Ranking of Scientific Papers for World Universities http://nturanking.lis.ntu.edu.tw (Accessed on 31.07.2019).

Parvez, N., Agrawal, A., 2019. Assessment of sustainable development in technical higher education institutes of India. J. Clean. Prod. 214, 975-994. https://doi.org/10.1016/j.jclepro.2018.12.305.

Peng, S., Cui, H., Ji, M., 2018. Sustainable rainwater utilization and water circulation model for green campus design at Tianjin University. J. Sustainable Water Built Environ. 4 (1), 04017015. https://doi.org/10.1061/JSWBAY.0000841. 
Quacquarelli Symonds, 2019. QS Top Universities https://www.topuniversities.com/universityrankings (Accessed on 31.07.2019).

Ramanujan, D., Zhou, N., Ramani, K., 2019. Integrating environmental sustainability in undergraduate mechanical engineering courses using guided discovery instruction. J. Clean. Prod. 207, 190-203. https://doi.org/10.1016/j.jclepro.2018.09.191.

Rwelamila, P.M.D., Purushottam, N., 2016. Strategic project management as an innovative approach for sustainable green campus buildings in Africa. Smart Sustain. Built Environ. 5(3), 261-271. https://doi.org/10.1108/SASBE-09-2015-0029.

Savely, S.M., Carson, A.I., Delclos, G.L., 2007. An environmental management system implementation model for U.S. colleges and universities. J. Clean. Prod. 15(7), 660-70. https://doi.org/10.1016/i.jclepro.2006.01.013.

Schmitt C.T., Palm S., 2018. Sustainability at German Universities: The University of Hamburg as a Case Study for Sustainability-Oriented Organizational Development, in: Leal Filho W. (Ed.) Handbook of Sustainability Science and Research. World Sustainability Series. Springer, Cham. https://doi.org/10.1007/978-3-319-63007-6 39.

Shanghai Ranking, 2019. Jiao Tong University Academic Ranking of World Universities (ARWU) http://www.shanghairanking.com/index.html (Accessed on 31.07.2019).

Sharp, L., 2002. Green campuses: the road from little victories to systemic transformation. Int. J. Sustain. High. Educ. 3 (2), 128-145. https://doi.org/10.1108/14676370210422357.

Shi, H., Lai, E., 2013. An alternative university sustainability rating framework with a structured criteria tree. J. Clean. Prod. 61, 59-69. https://doi.org/10.1016/i.jclepro.2013.09.006.

Shuqin, C., Minyan, L., Hongwei, T., Xiaoyu, L., Jian, G., 2019. Assessing sustainability on Chinese university campuses: Development of a campus sustainability evaluation system and its application with a case study. J. Build. Eng. 24, 100747. https://doi.org/10.1016/i.jobe.2019.100747.

Stough, T., Ceulemans, K., Lambrechts, W., Cappuyns, V., 2017. Assessing sustainability in higher education curricula: a critical reflection on validity issues. J. Clean. Prod. 172, 4456-4466. https://doi.org/10.1016/j.jclepro.2017.02.017.

Sustainable Development Goals Knowledge Platform, 2019. Higher Education Sustainability Initiative https://sustainabledevelopment.un.org/sdinaction/hesi (Accessed on 31.07.2019).

Suwartha, N., Sari, R.F., 2013. Evaluating UI GreenMetric as a tool to support green universities development: assessment of the year 2011 ranking. J. Clean. Prod. 61, 46-53. https://doi.org/10.1016/i.jclepro.2013.02.034.

Tan, H., Chen, S., Shi, Q., Wang, L., 2014. Development of green campus in China. J. Clean. Prod. 64, 646-653. https://doi.org/10.1016/j.jclepro.2013.10.019.

Thürer, M., Tomašević, I., Stevenson, M., Qu, T., Huisingh, D., 2018. A systematic review of the literature on integrating sustainability into engineering curricula. J. Clean. Prod. 181, 608-617. https://doi.org/10.1016/i.jclepro.2017.12.130.

Times Higher Education, 2019. Times Higher Education (THE) World University Rankings https://www.timeshighereducation.com/world-university-rankings (Accessed on 31.07.2019).

UI GreenMetric, 2019. University of Indonesia GreenMetric World University Rankings http://greenmetric.ui.ac.id (Accessed on 31.07.2019).

UI GreenMetric Methodology, 2019. University of Indonesia GreenMetric World University Rankings Methodology http://greenmetric.ui.ac.id/methodology-new/ (Accessed on 31.07.2019). 
Venetoulis, J., 2001. Assessing the ecological impact of a university: the ecological footprint for the University of Redlands. Int. J. Sustain. High. Educ. 2 (2), 180-196. https://doi.org/10.1108/14676370110388381.

Wang, Y., Shi, H., Sun, M., Huisingh, D., Hansson, L., Wang, R., 2013. Moving towards an ecologically sound society? Starting from green universities and environmental higher education. J. Clean. Prod. 61, 1-5. https://doi.org/10.1016/i.jclepro.2013.09.038.

Xiong, H., Fu, D., Duan, C., Chang'E, L., Yang, X., Wang, R., 2013. Current status of green curriculum in higher education of Mainland China. J. Clean. Prod. 61, 100-105. https://doi.org/10.1016/i.jclepro.2013.06.033.

Yuan, X., Zuo, J., Huisingh, D., 2013. Green Universities in China-what matters?. J. Clean. Prod. 61, 3645. https://doi.org/10.1016/i.jclepro.2012.12.030.

Zhao, W., Zou, Y., 2018. Variation of greenness across China's universities: motivations and resources. Int. J. Sustain. High. Educ. 19 (1), 48-66. https://doi.org/10.1108/IJSHE-10-2016-0196. 